\title{
Test-retest reliability evaluation of the Escala de Conciencia Cultural para Estudiantes de Terapia Ocupacional en América Latina (ECCETO) - Cultural Awareness Scale for Occupational Therapy Students in Latin America
}

\author{
Daniela Castro, Synneve Dahlin-Ivanoff, Lena Mårtensson \\ Departament of Health and Rehabilitation/Occupational Therapy, University of Gothenburg, Gothenburg, \\ Västra Götaland, Sweden.
}

\begin{abstract}
Introduction: Cultural awareness is an important consideration in healthcare, particularly in occupational therapy. Personal values are often challenged in service provision. Culturally relevant scales are needed to evaluate this across the professional education. Evaluation of psychometric properties is a critical issue in scale development. The test - retest reliability of the Escala de Conciencia Cultural para Estudiantes de Terapia Ocupacional en América Latina (ECCETO), (Cultural Awareness Scale for Occupational Therapy students in Latin America) has not yet been evaluated. Objective: To evaluate the test-retest reliability of the ECCETO. Method: The Svensson's method was used to evaluate the ECCETO responses of 10 newly graduated Chilean occupational therapists and 26 occupational therapy students from four Latin American countries. Results: The scale had test-retest reliability, based on a reduced number of items presenting systematic disagreement, and showed good internal consistency. Conclusion: There were differences in the scale's categories and between the study phases. Using the scale in larger groups of students may support reflective opportunities that promote early development of cultural awareness. Cultural awareness should be included in occupational therapy education in Latin America and worldwide. Adaptations of the ECCETO, should carefully consider the local practice context to preserve the cultural relevance in different regions.
\end{abstract}

Keywords: Culture; Evaluation; Education, Higher; South America.

\section{Avaliaçáo da confiabilidade teste-reteste da Escala de Conciencia Cultural para Estudiantes de Terapia Ocupacional en América Latina (ECCETO) - Escala de Consciência Cultural para Estudantes de Terapia Ocupacional na América Latina}

\begin{abstract}
Resumo: Introdução: A consciência cultural é considerada importante na área da saúde, especialmente em terapia ocupacional. Valores e significados pessoais muitas vezes são desafiados na prestação de serviços terapêuticos, por isso as escalas, que precisam ser culturalmente relevantes para os contextos locais de prática, são necessárias para avaliar esses aspectos da educação profissional. A avaliação das propriedades psicométricas é uma questão crítica no desenvolvimento dessas escalas. O teste-reteste da Escala de Consciência Cultural para Estudantes de Terapia Ocupacional na América Latina (ECCETO) ainda não foi avaliado. Objetivo: Avaliar a confiabilidade teste-reteste da ECCETO. Método: O método de Svensson para dados pareados ordinais foi utilizado para avaliar as respostas da ECCETO de 10 terapeutas ocupacionais chilenos recém-formados e de 26 estudantes de terapia ocupacional de
\end{abstract}

Corresponding author: Daniela Castro, Department of Health and Rehabilitation/Occupational Therapy, Institute of Neuroscience and Physiology, The Sahlgrenska Academy, University of Gothenburg, Arvid Wallgerens Backe, House 2, 2nd floor, Gothenburg, 455,405 30, Sweden, e-mail: daniela.castro@neuro.gu.se

Received on June 23, 2016; $1^{\text {st }}$ Revision on Sept. 26, 2016; Accepted on Oct. 12, 2016 
quatro países latino-americanos. Resultados: A escala apresentou confiabilidade teste-reteste, baseado em um número reduzido de itens que apresentou discordância sistemática, e mostrou boa consistência interna. Conclusão: Havia diferenças nas categorias da escala e entre as diferentes fases do estudo. O uso da escala em grupos de estudantes pode apoiar oportunidades reflexivas que promovam o desenvolvimento precoce de consciência cultural na educação profissional. Significância do estudo: A consciência cultural deve ser incluída na educação de terapia ocupacional na América Latina e no mundo. Adaptações da ECCETO ou escalas futuras devem considerar cuidadosamente o contexto ocupacional de prática terapêutica local para preservar a relevância cultural em diferentes países ou regiões.

Palavras-chave: Cultura, Avaliação, Educação Superior, América do Sul.

\section{Introduction}

The need for cultural awareness in occupational therapy has been acknowledged in literature (CASTRO; DAHLIN-IVANOFF; MÅRTENSSON, 2014; KINÉBANIAN; STOMPH, 2009; ODAWARA, 2005). Cultural awareness can be described as the affective dimension of cultural competence, including self-exploration of values, meanings and heritage in personal and professional terms (CAMPINHA-BACOTE, 2002; KINÉBANIAN; STOMPH, 2009; REW et al., 2003). It also includes students' and practitioners' reflections about the cultural expressions of the people they provide services to and work with (CAMPINHA-BACOTE, 2002; REW et al., 2003). Therefore, cultural awareness should be a skill that is introduced and assessed across professional education using valid and reliable instruments (CHEUNG; SHAH; MUNCER, 2002). Reliable instruments to assess cultural awareness may support strengthening of the curricula, including implementing actions to promote cultural awareness and identify key issues for local practices (FITZGERALD; CRONIN; CAMPINHA-BACOTE, 2009; KINÉBANIAN; STOMPH, 2009). To our knowledge, only one valid and reliable instrument is available to assess cultural awareness in occupational therapy. The Cultural Awareness and Sensitivity Questionnaire (CASQ), is an instrument initially developed for English occupational therapy students (CHEUNG; SHAH; MUNCER, 2002). Its psychometric properties have been tested and it has been used in studies in the United States, the United Kingdom and Australia (CHERRY et al., 2009; CHEUNG; SHAH; MUNCER, 2002; KALE; SWEE HONG, 2007; MURDEN et al., 2008; RASMUSSEN; LLOYD; WIELANDT, 2005).

Valid and reliable scales or similar instruments are crucial in the assessment of skills and competences in social, educational and health care sciences (AIKEN, 2003; DEVELLIS, 2012). The results obtained from these scales are central to implementing satisfactory decision-making processes in health care and relevant educational outcomes (DOMHOLDT, 2005; MUNIIZ et al., 2001). However, most of the scales currently used in health care have been developed and reported in English-speaking and Western European countries (MUNIZ et al., 2001), and are influenced by the cultures in which they were developed. Importing foreign scales is a common practice in non-English-speaking regions of the world. However, imported scales are often used despite the fact that they have not always been appropriately adapted for the local practice contexts (MUNIIZ et al., 2001; WECHSLER et al., 2014). The psychometric properties of a scale must be tested during the process of development or adaptation to minimise concerns about quality (AIKEN, 2003; KUMAS-TAN et al., 2007). Reliability is one of these quality characteristics, and is defined as the consistency of a scale (AIKEN, 2003; DEVELLIS, 2012). There are different forms of reliability, such as the analysis of variance, continuous versus dichotomous items, internal consistency, and correlations between the scale's scores (DEVELLIS, 2012). Test-retest reliability measures the correlations between repeated measures on the sample on two different occasions (DEVELLIS, 2012). This identifies whether or not the assessments remain constant over a given period of time (DEVELLIS, 2012).

Because of the lack of instruments measuring cultural awareness developed in non-English-speaking countries, the Escala de Conciencia Cultural para Estudiantes de Terapia Ocupacional en América Latina - ECCETO, (Cultural Awareness Scale for Occupational Therapy Students in Latin America) was recently developed. The items on this scale were based on a qualitative study that explored Chilean occupational therapists' reasoning about culture based on their personal and practice experiences (CASTRO; DAHLIN-IVANOFF; MÅRTENSSON, 2016b). The content validity of the scale was tested in a qualitative Delphi study with experts from 
four Latin American Spanish-speaking countries (CASTRO; DAHLIN-IVANOFF; MÅRTENSSON, 2016a). However, further psychometric testing of the quality of the scale is required, before it can be used in practice. Therefore, the aim of this study was to evaluate the test-retest reliability of the ECCETO.

\section{Method}

\subsection{Study design}

This study was conducted over a 6 -month period in 2015 in Spanish-speaking countries in Latin America. The inclusion criteria were participants who were newly-graduated occupational therapists, and final year students with fieldwork experiences. Fieldwork experiences provide opportunity for students to exercise their cultural awareness in real practice situations. Eligible participants must have conducted or be conducting their professional studies in programs approved by the World Federation of Occupational Therapists - WFOT in the Latin-American region (WORLD..., 2002, 2014). Programs in five countries in the study region met this criterion: Argentina, Chile, Colombia, Mexico and Venezuela. Participants from one program per country were invited to participate in the study based on these programs' active participation in a previous study on the development of the scale (CASTRO; DAHLIN-IVANOFF; MÅRTENSSON, 2016a). Participants from one of the programs could not be included in the data collection because of administrative delays. Based on this, and the slow response rate, students from an additional program were invited to participate.

\subsection{The scale}

The ECCETO includes 30 items in three categories: "personal culture" or perceptions about personal values and cultural background(s) - items 1-10; "culture in the occupational therapy profession" covering perceptions regarding the professional knowledge and practice in Latin America - items 11-18; and "culture in the therapeutic processes and the persons that I work with" covering perceptions about therapeutic strategies and potential dilemmas in practice, items 19- 30 (CASTRO; DAHLIN-IVANOFF; MÅRTENSSON, 2016a). Each item has four possible ordinal levels of agreement (from no agreement to totally agree) (CASTRO; DAHLIN-IVANOFF; MÅRTENSSON, 2016a). The scale also includes a section for qualitative comments. A detailed description of the development and construction of the scale has been published elsewhere (CASTRO; DAHLIN-IVANOFF; MÅRTENSSON, 2016a).

\subsection{Test-retest reliability evaluation}

The test-retest reliability was selected to evaluate the scale in two phases. The retest was applied at a 2-week interval (14 days) after the test, as has been recommended (NUNNALLY; BERNSTEIN, 1994). This timeframe allows participants to have forgotten their previous responses, while retaining a similar perception of the phenomena, as it is unlikely that major changes occurred regarding their status (NUNNALLY; BERNSTEIN, 1994).

\subsection{Participants: phase one}

The goals of this phase were to obtain an initial indication of the test-retest reliability of the scale and an indication of the need for clarification of items for the next phase. Specific inclusion criteria for participation in this phase were occupational therapists who: graduated within 3 months of the start of the study, and belonged to the same selected WFOT-approved program. A convenience sampling strategy was adopted (KLINE, 2005), using the authors' previous professional contacts with a program in Chile. Ten people were randomly selected from the newly-graduated group and invited to participate. All invited participants provided consent to take part in this phase of the study and there were no drop outs (Table 1).

\subsection{Participants: phase two}

This phase aimed to evaluate the test-retest reliability of the ECCETO using a sample of the target group. Specific inclusion criteria for this phase were: enrolment as a final-year occupational therapy student, and both theoretical training and fieldwork experiences (FITZGERALD et al., 2009; REW et al., 2014). A convenience sampling strategy was also used in this phase (KLINE, 2005), using the authors' previous contact with programs

Table 1. Characterization of the participants in phase one $(n=10)$.

\begin{tabular}{lc}
\hline $\begin{array}{c}\text { Semesters required to } \\
\text { complete education }\end{array}$ & 10 \\
\hline Mean Age & 23.8 \\
Range of Age & $21-25(n=9)$ \\
Gender & $26-30(n=1)$ \\
Employed at the moment & $8 \mathrm{~F}: 2 \mathrm{M}$ \\
\hline
\end{tabular}


that participated in the previous study (CASTRO; DAHLIN-IVANOFF; MÅRTENSSON, 2016a). In total, 215 students from the selected programs were invited by the heads of these programs to participate. Thirty-one students consented to participate, representing $14.41 \%$ of the eligible students. Five participants dropped out for unknown reasons before participation in the retest, leaving a final sample of 26 students (12.09\%) (Table 2).

\subsection{Procedures}

All communication with participants (and heads of programs) was conducted by email in Spanish. Reminders were sent (after 3 days), when required, to non-responders. Informative personalised messages were used to improve the response rate, and these messages included a direct link to the scale to avoid problems downloading attachments. Checked and accurate lists of email lists and reminders were used as recommended (COPE, 2014; MCPEAKE; BATESON; O’NEILL, 2014).

\subsection{Phase one procedures}

The first author contacted the participants and provided them with a general overview of the study. After agreeing to take part, participants received an extended information sheet about the study, an informed consent form and an identification code for use in data storage and analysis. After the consent form was signed and returned, participants were provided with a link to an electronic version of the scale. All items except qualitative comments were mandatory. Electronic scales are recommended given the increased access to computers and the
Internet, reduced costs, time-saving, ready-foranalysis responses, increased anonymity, decreased chances of human error, access to participants living in different locations, no logistic aspects as for in-person meetings, and they are environment friendly (COPE, 2014; MCPEAKE; BATESON; O’NEILL, 2014).

Once the test re-test was completed, each participant received confirmation of completion. When responses from all participants in this phase were received, data analysis was performed. The findings for this stage provided a first indication of the test-retest reliability, and informed any necessary revision of the items. Modifications of items with the lowest indications of test-retest reliability were considered. This was supported by the qualitative comments provided by the participants, and a focus on keeping the original meaning of the items and to reach stronger indications of reliability in the upcoming round.

\subsection{Phase two procedures}

An invitation letter was sent to the heads of the chosen programs. They were asked to invite all students matching the inclusion criteria to take part in the study, and received a copy of the documents sent to students for their information. Invited students who consented to participate provided their name and an email address. The test was conducted as soon as each student consenting to take part in the study replied. For this stage of data collection, implementation of the test-retest and communication with the participants proceeded in a similar way to phase one. A flowchart summarising procedures, data collection and data analysis in both phases is presented in Figure 1.

Table 2. Characterization of the participants in Phase two $(n=26)$.

\begin{tabular}{|c|c|c|c|c|c|c|}
\hline Criteria & Total & $\begin{array}{l}\text { Program } 1 \\
\text { Argentina }\end{array}$ & $\begin{array}{c}\text { Program } 2 \\
\text { Chile }\end{array}$ & $\begin{array}{c}\text { Program } 3 \\
\text { Chile }\end{array}$ & $\begin{array}{c}\text { Program } 4 \\
\text { Mexico }\end{array}$ & $\begin{array}{l}\text { Program } 5 \\
\text { Venezuela }\end{array}$ \\
\hline $\begin{array}{l}\text { Students in } \\
\text { the last year } \\
\text { of training }\end{array}$ & 215 & 67 & 59 & 46 & 18 & 25 \\
\hline Participants & $26(12 \%)$ & $3(4 \%)$ & $18(31 \%)$ & $1(2 \%)$ & $3(17 \%)$ & $1(4 \%)$ \\
\hline $\begin{array}{l}\text { Semesters } \\
\text { required to } \\
\text { complete } \\
\text { education }\end{array}$ & 9 & 8 & 10 & 10 & 9 & 8 \\
\hline Mean Age & 23.3 & 24 & 23.7 & 23 & 21.3 & 20 \\
\hline Range of Age & $\begin{array}{c}\leq 20(n=2) \\
21-25(n=20) \\
26-30(n=4)\end{array}$ & $\begin{array}{r}\leq 20(n=0) \\
21-25(n=2) \\
26-30(n=1)\end{array}$ & $\begin{array}{c}\leq 20(n=0) \\
21-25(n=15) \\
26-30(n=3)\end{array}$ & $\begin{array}{r}\leq 20(n=0) \\
21-25(n=1) \\
26-30(n=0)\end{array}$ & $\begin{array}{r}\leq 20(n=1) \\
21-25(n=2) \\
26-30(n=0)\end{array}$ & $\begin{array}{r}\leq 20(n=1) \\
21-25(n=0) \\
26-30(n=0)\end{array}$ \\
\hline Gender & $12 \mathrm{~F}: 1 \mathrm{M}$ & $3 \mathrm{~F}: 0 \mathrm{M}$ & $17 \mathrm{~F}: 1 \mathrm{M}$ & $0 \mathrm{~F}: 1 \mathrm{M}$ & $3 \mathrm{~F}: 0 \mathrm{M}$ & $1 \mathrm{~F}: 0 \mathrm{M}$ \\
\hline
\end{tabular}




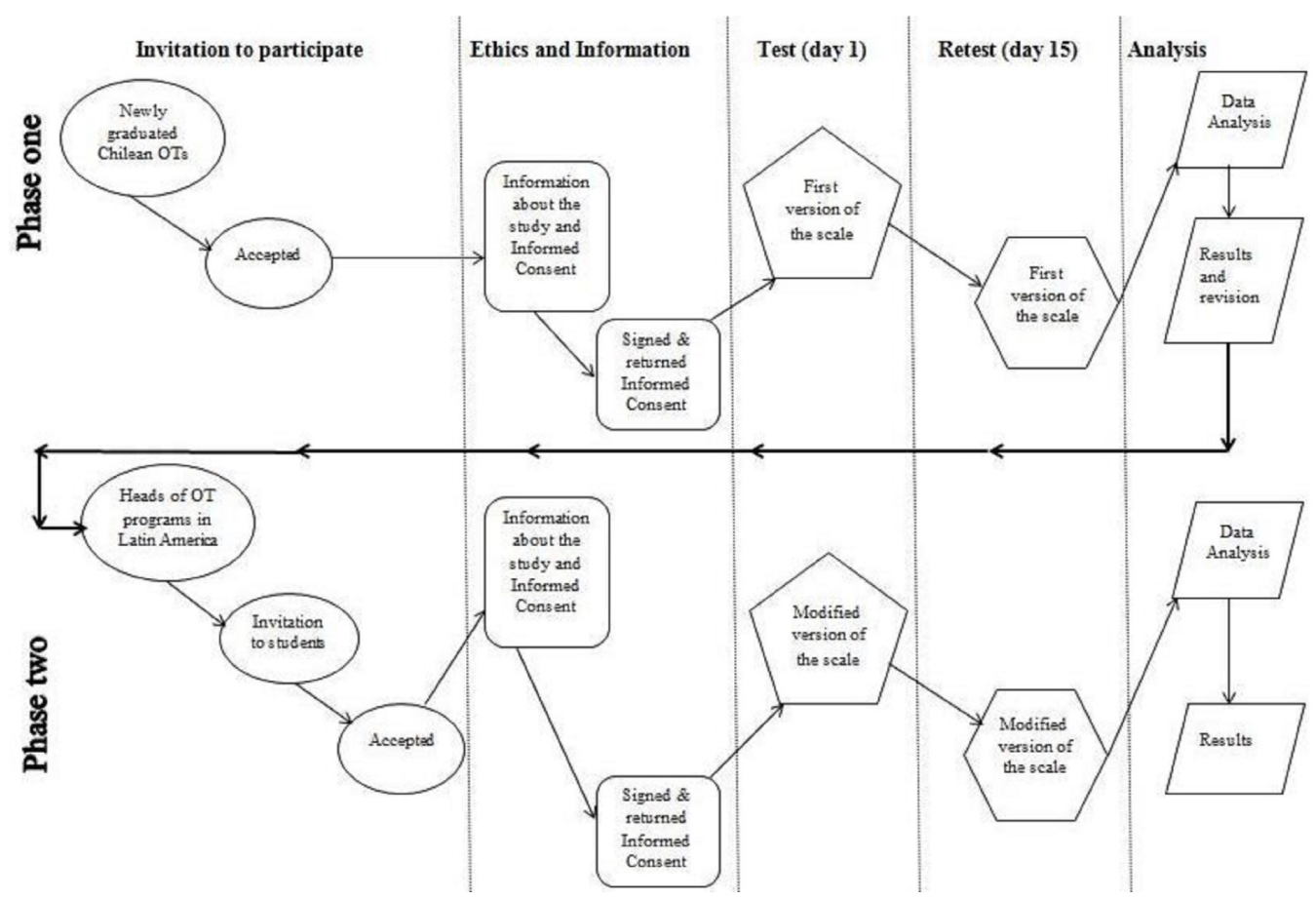

Figure 1. Flowchart of the phases.

\subsection{Ethics}

Ethical permission was provided by a Chilean university, considering the previous study and the current one (CASTRO; DAHLIN-IVANOFF; MÅRTENSSON, 2016a). Participants received written information presenting a summary of the study, as well as an informed consent form. They had the opportunity to contact the researchers if they needed clarification at any stage of the research process, even after their participation had concluded. The data were treated confidentially throughout the study and handled exclusively by the authors.

\subsection{Statistical analysis}

The data were presented as ordered categorical data, and the Svensson method was used for analysis (SVENSSON, 1993, 1998). This method considers rank-transformable statistics and allows the identification of agreement and disagreement within individual (occasional) and group (systematic) levels between the test and retest (SVENSSON, 1998). A two-way bivariate ranking procedure was performed to identify the level of disagreement using the Svensson's method free software (Version 1.1.2) (AVDIC; SVENSSON, 2012). Contingency tables were constructed to identify how the paired assessments were distributed for each item (SVENSSON, 1993).
Data were analysed for all items in both phases, using the calculations detailed below:

i. The first step aimed to identify the presence of systematic disagreement. This was identified by the relative rank position ( $R P)$. RP values oscillate between -1 and 1 . The higher the RP value, the higher the variation. An RP close to zero indicates that change over time is not relevant (SVENSSON, 1998). Subsequently, relative operating characteristics (ROC) curves were constructed. ROC-curves indicate systematic disagreement in a scale, demonstrating a potential lack of stability (SVENSSON, 1993). This is also known as marginal distribution between the test and retest. The disagreement can be illustrated with a curve that compares the cumulative proportions, with 0.0 as the start (SVENSSON, 1993). If the curve is linear and follows the diagonal line, no systematic disagreement exists between the test and the retest. If the curve is concave or convex, disagreement is represented by the RP values (SVENSSON, 1993). In addition, the relative concentration (RC) was calculated. This indicates systematic disagreement, showing if some respondents used a limited part of the scale on one of the tests, expressed by $s$-type 
ROC curves. The values vary from -1 to 1 ; 0 indicates no disagreement, meaning the item is stable (SVENSSON, 1998). How the observations are dispersed in the contingency table may indicate occasional disagreement. This is indicated by the variation in the relative variance $(\mathrm{RV})$ with values oscillating between 0 and 1 . A higher RV indicates more variability (SVENSSON, 1998).

ii. Another step was conducted to explore the distribution of the paired assessments. For each item a contingency table was constructed. The percentage agreement (PA) was obtained to get an indication of the degree of agreement between the pairs of ordinal data, compared within a set period of time (2 weeks) (SVENSSON, 2001).

iii. Finally, standard error (SE) was calculated. A SE larger than 2 for the RV, RP and RC values, indicates strong disagreement of the corresponding parameter (SVENSSON, 1993).

\section{Results and Revisions}

\subsection{Phase one}

This phase aimed to obtain an initial indication of the test-retest reliability of the scale and to identify items that required clarification for the next phase.

The ROC-curves showed systematic disagreement for six of the 30 items (items 7, 8, 12, 18, 19 and 29). Occasional $(\mathrm{RV}>0.10)$ and systematic disagreement (RP or RC $> \pm 0.10$ ) were calculated for these items, and all items showed significant systematic disagreement with values outside \pm 2 SE. For example, item 12 ("I believe that the occupational therapists share meanings and values as part of the professional identity") had RP -0.21 and RC 0.28 , and item 29 ("The idea of working with people who belong to a culture different from mine makes me feel fearful or insecure regarding my skills as an occupational therapist") had $\mathrm{RP} 0.53$ and RC -0.11 . The contingency tables and ROC curves for these items are presented (Figure 2). In both cases, the disagreements were allocated a distant position from the diagonal.

High levels of individual occasional disagreement (RV) were also identified in six items (items 12, 13, 15, 18, 19 and 22). For example, item 19 ("It is important to put my personal values aside when I interact with the people I meet in my internship") had $\mathrm{RV}$ of 0.12 , and item 22 ("I have been able to notice the cultural differences I have with the people I have met during my internship") had RV of 0.43 . Across these items, the RP values ranged from -0.37 to 0.53 and the $\mathrm{RC}$ values ranged from -0.19 to 0.36 . The $\mathrm{RV}$ values ranged from 0.00 to 0.54 . Detailed results are presented in Table 3.

For all items, the PA values ranged from $30.0 \%-100.0 \%$. The median was $60.0 \%$, and the mean was $64.0 \%$. Nine items showed good agreement $(\mathrm{PA} \geq 80.0 \%)$ (KAZDIN, 1977) and 11 items had fairly good agreement (PA 60.0\%-79.0\%). The remaining 10 items had poor agreement, with $\mathrm{PA}$ values $\leq 59.0 \%$ (Median 40.0\%).

Six items -that showed low indications of test-retest reliability in some of the performed calculations (i.e. PA, RV, RP) - were clarified based on the indications of low test-retest reliability shown in this phase (items 19, 20, 22, 25, 26 and 29), and two items were deleted (items 12 and 18). Two items (items 4 and 14) were used in the next version of the scale without changes, as they represented

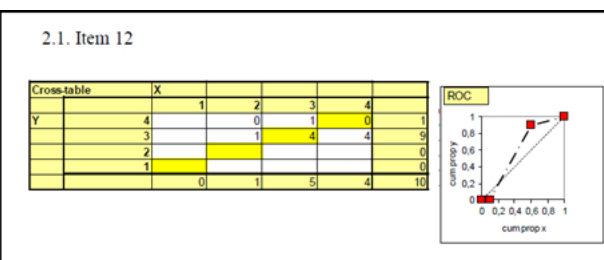

2.2. Item 29

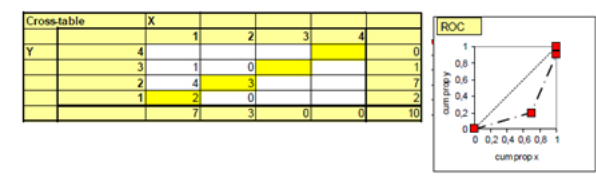

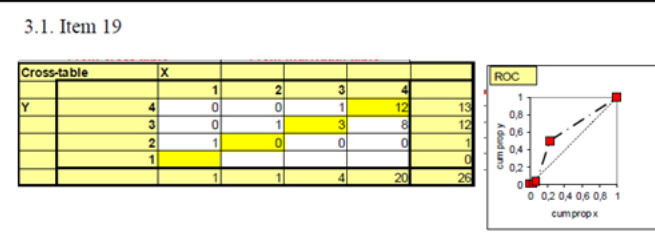

3.2. Item 23

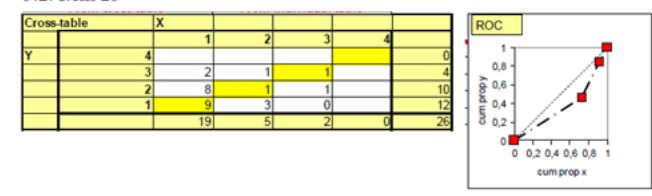

Figure 2. Examples of contingency tables and ROC-curves for two items for each phase (Items 12 and 29 on phase 1, Items 19 and 23 on phase 2). 


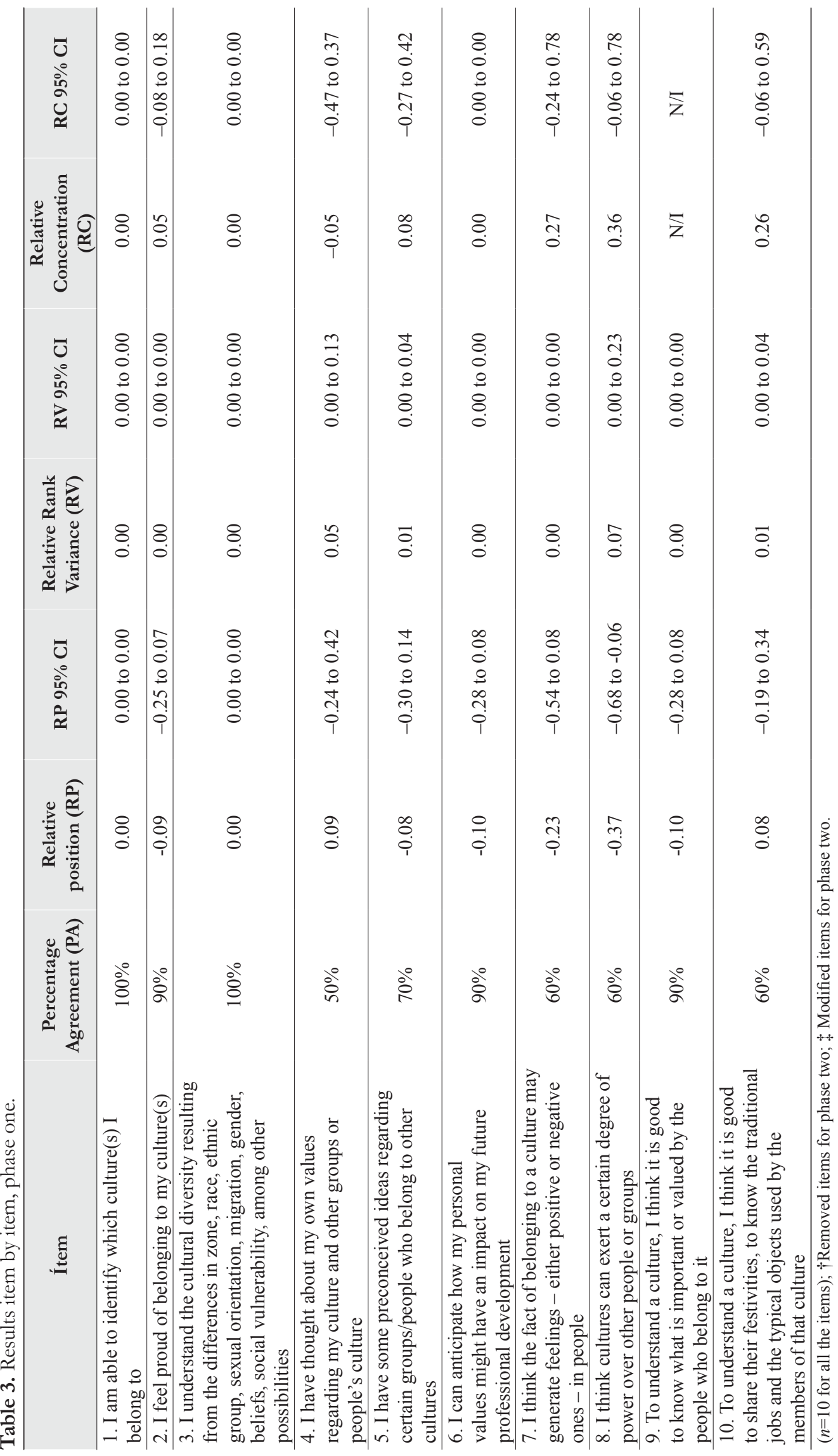




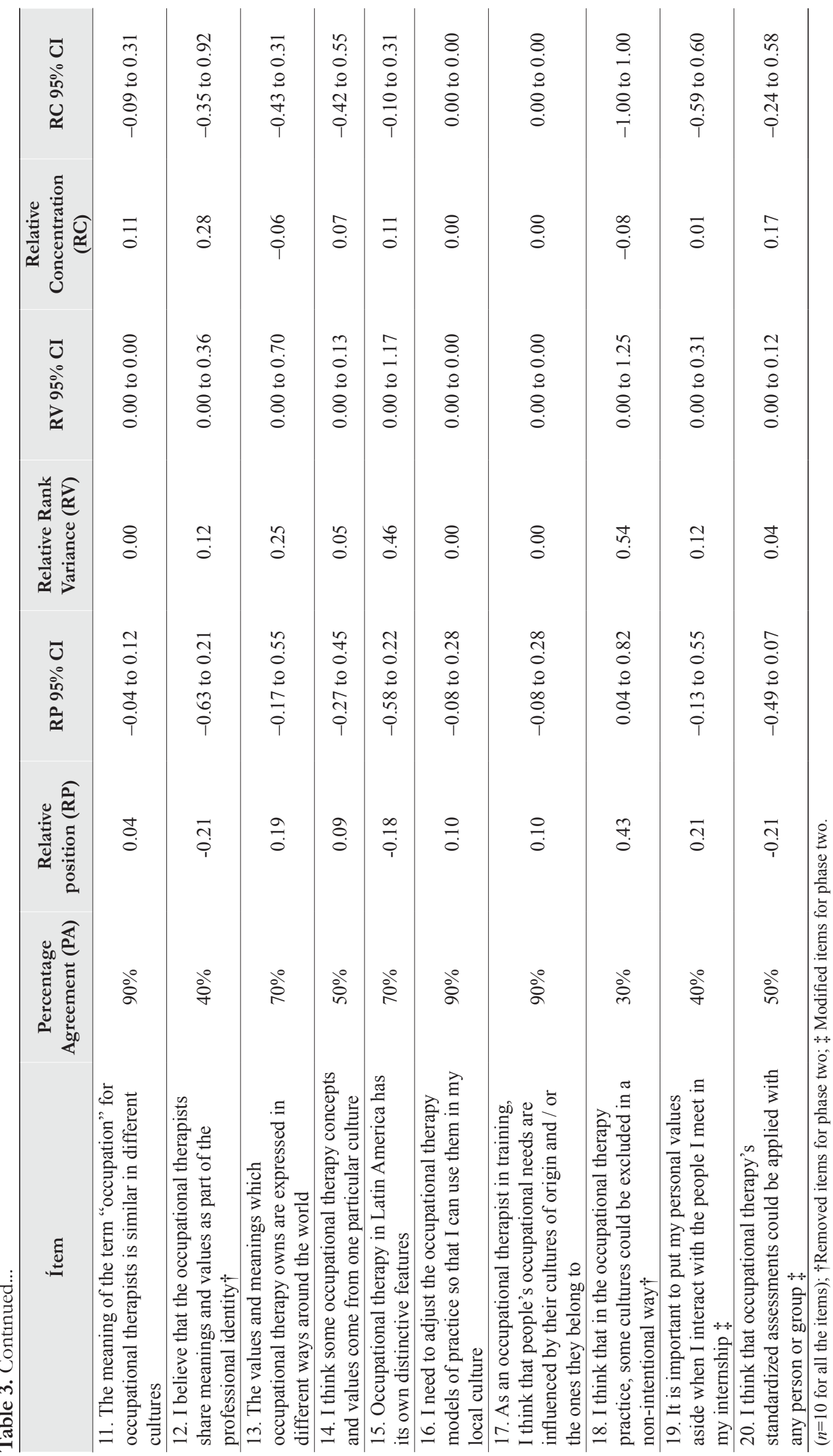




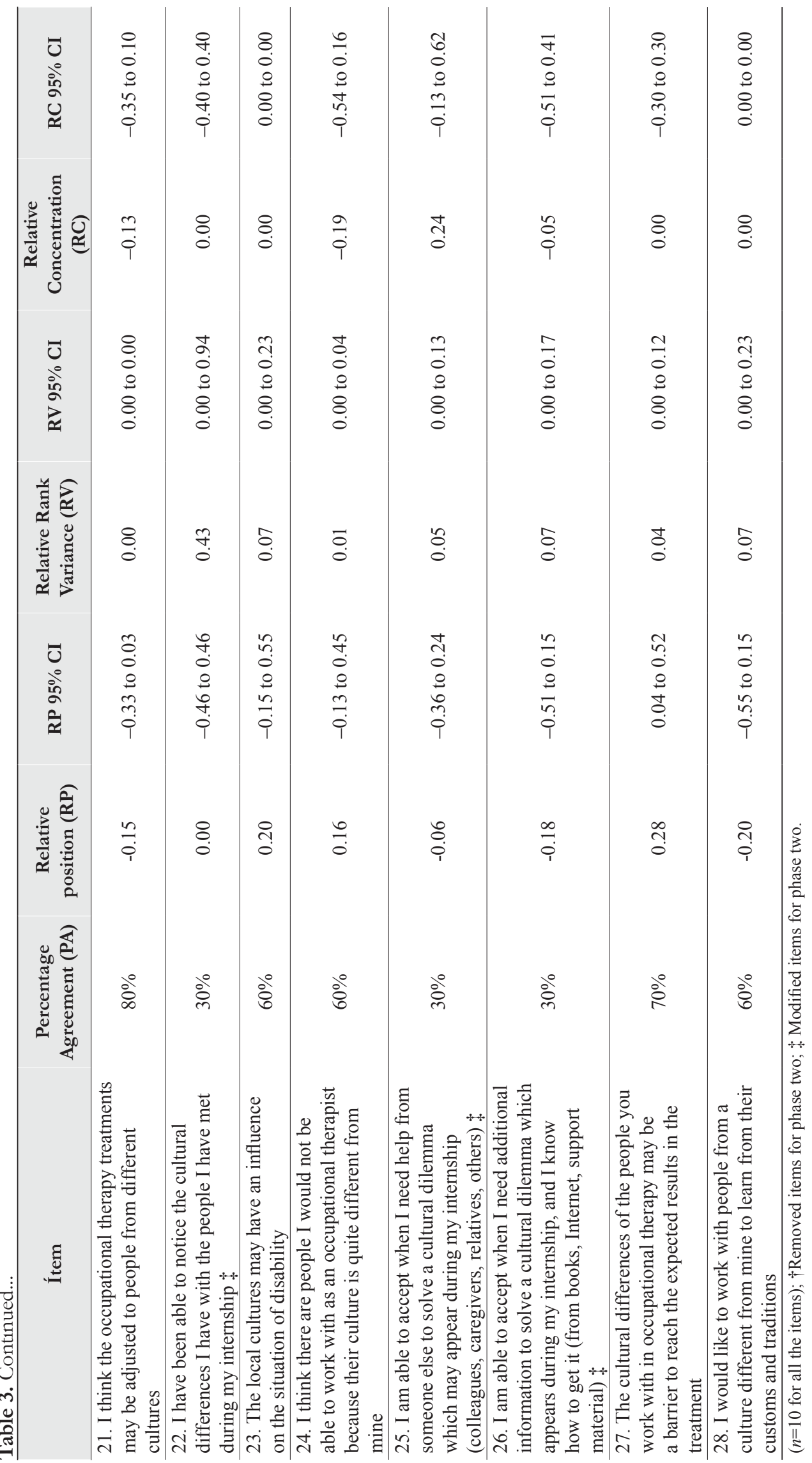




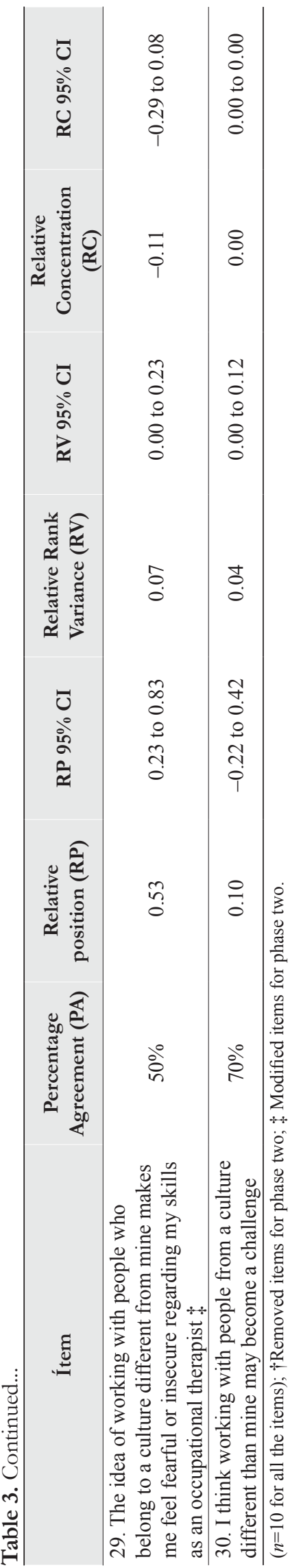


the definition of cultural awareness and critical approaches in the profession. Two new items were introduced to replace the deleted ones, meaning that the scale still comprised 30 items. These new items were based on topics identified as relevant during the scale development (culturally relevant knowledge and cultural dilemmas in practice). The new items were

I think the current theories in occupational therapy are culturally relevant, independent of the context in which they are used" and "I am able to identify a cultural dilemma during my internship when it appears.

\subsection{Phase two}

In phase two, the ROC-curve analysis identified systematic disagreement in two items. Both items showed instability with the high RP, RC and/or RV values: item 19, "I think some of the standardized occupational therapy assessments may have some limitations when used in certain cultural contexts" (RP -0.24 and RC 0.20) and item 23 "I think there are people I would not be able to work with as an occupational therapist because their culture is quite different from mine" (RP 0.27 and RV 0.15). Contingency tables and ROC-curves are presented for both items. The agreement diagonals in the contingency tables illustrate a systematic disagreement (Figure 2). The RV values ranged from $0.00-0.29$ and the RP values ranged from -0.24 to 0.27 . The RC range was -0.29 to 0.26 .

Five items showed indications of instability based on the RP, RC and RV values. For example, item 15 ("I need to adjust the occupational therapy models of practice so that I can use them in my local culture") showed RC of 0.16; RV of 0.14 and RC of 0.15 , and item 27 ("The cultural differences of the people you work with in occupational therapy may be a barrier to reach the expected results in the treatment") showed RP of 0.18 ; RV of 0.15 and $\mathrm{RC}$ of -0.18). The new items in this phase (items 17 and 24), showed fairly good PA values (62.0\% and $69.0 \%$ respectively). The PA values increased for the items that were modified following phase one with a range of $+8.0 \%$ to $+43.0 \%$. However, two items had indications of instability based on their RP and RC values (item 19: RP -0.24 , RC 0.20 ; and item 29: RP 0.15, RC 0.20). Items 4 and 14 were not changed, despite low PA values in phase one showing poor agreement $(46.0 \%$ and $54.0 \%$ respectively). Detailed results are presented in Table 4.
The 30 items on the scale had PA values ranging from $35.0 \%-85.0 \%$. The median was $58.0 \%$, and the mean was $61.0 \%$. Three items had good agreement (PA $\geq 80.0 \%)$ (KAZDIN, 1977), and 11 items showed fairly good agreement (PA 60.0\% - 79.0\%). The remaining 16 items had poor agreement, with $\mathrm{PA}$ values $\geq 59.0 \%$ (Median 54.0\%). No changes were made in the number, structure or content of the items following phase two.

\section{Discussion}

In terms of the test-retest reliability evaluation of the ECCETO, the more stable items were in the "personal culture" category. This indicates that participants presented a consistent understanding of the idea of culture, in theoretical terms. This may be because they had opportunity to address topics such as culture and diversity during professional education, as recommended by the WFOT minimum standards for education (WORLD..., 2002). The less reliable items were in the category "culture in the therapeutic processes and the persons that I work with" which addresses the skills, emotions and behaviour about culture in practice. As these concepts are challenged across fieldwork experiences, may be expected that students show different levels of development in this category. There are a number of reasons that might explain the differences in the findings between the two phases. The newly-graduated occupational therapists belonged to the same program and completed their education at the same time, and might share a more similar understanding of culture (BEAGAN, 2015; CASTRO; DAHLIN-IVANOFF; MÅRTENSSON, 2014). In contrast, students that belonged to programs in different countries might express differences that reflect the education and health demands in their local practice contexts (CASTRO; DAHLIN-IVANOFF; MÅRTENSSON, 2014; GALHEIGO, 2014). Therefore, the programs were similar in terms of quality, based on the approval provided by the WFOT (WORLD..., 2002, 2014), but differed on characteristics given by the local higher education systems (i.e. required time to complete professional education). In phase two, the students seemed to be closer to a more traditional understanding of culture, which has been a dominant trend in the profession (BEAGAN, 2015; CASTRO; DAHLIN-IVANOFF; MÅRTENSSON, 2014). This trend has been critically analysed in recent literature (BEAGAN, 2015; CASTRO; DAHLIN-IVANOFF; MÅRTENSSON, 2014). There were no major age differences between participants in phases one and two. Perceptions of cultural differences and therefore 


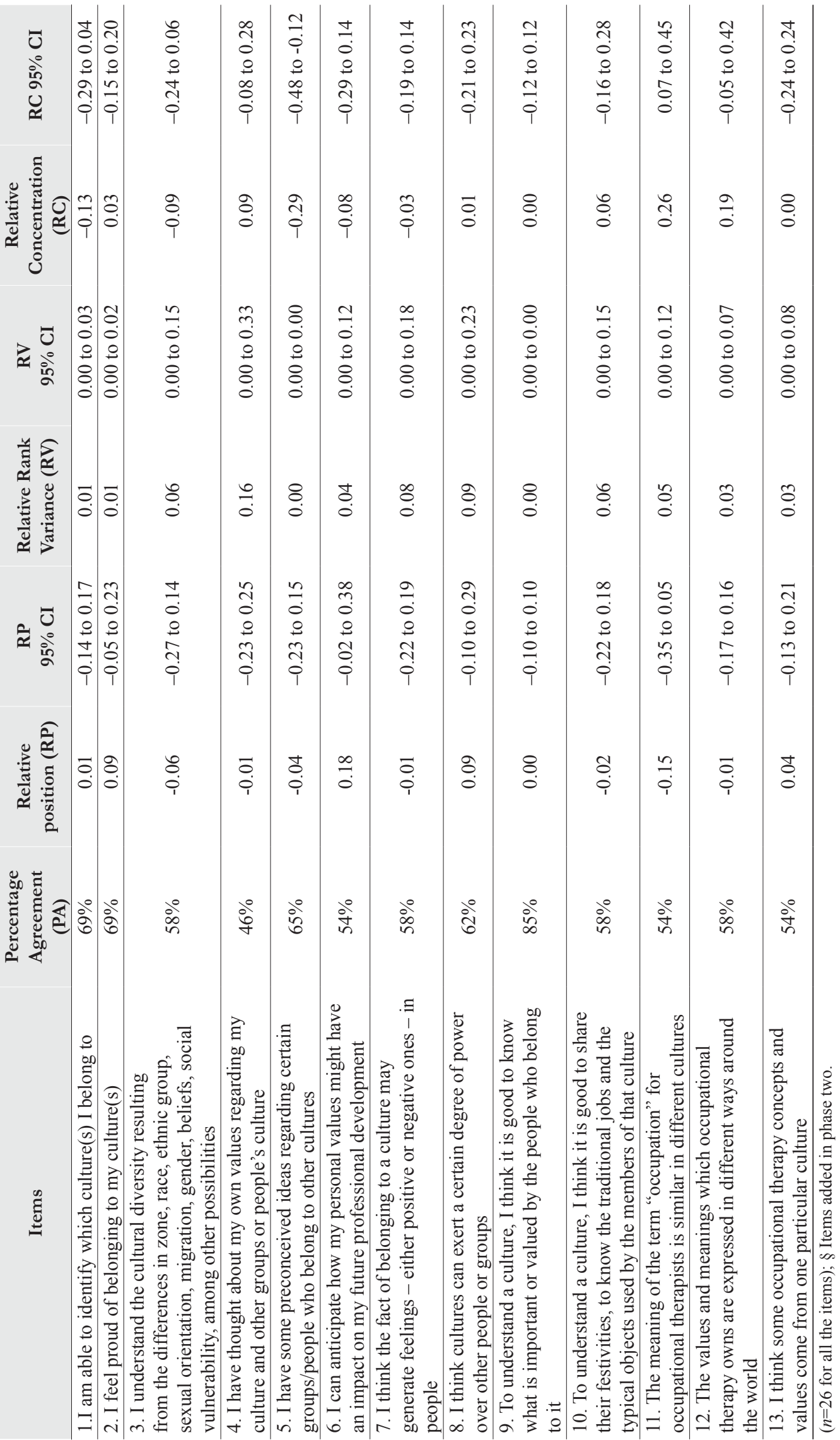




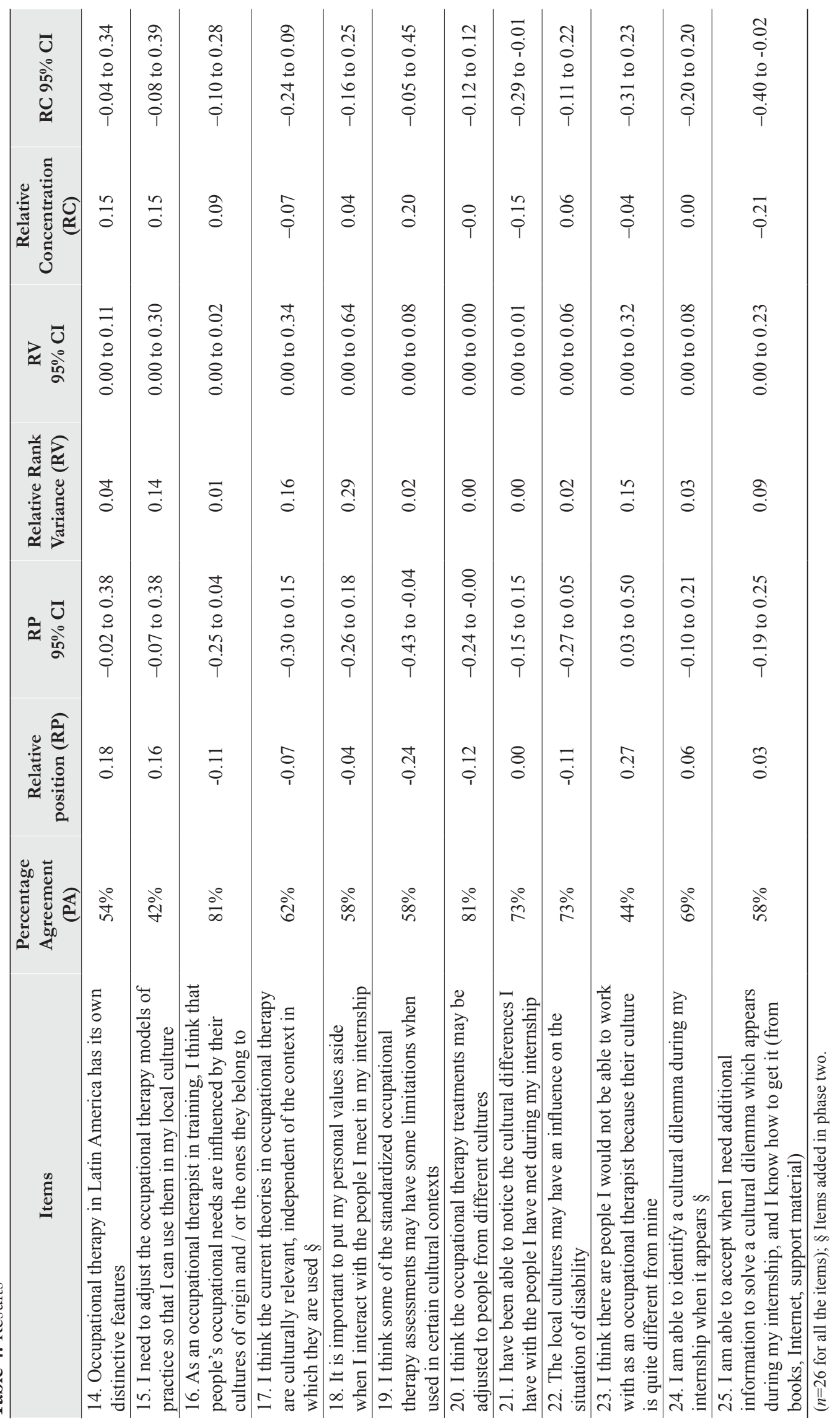




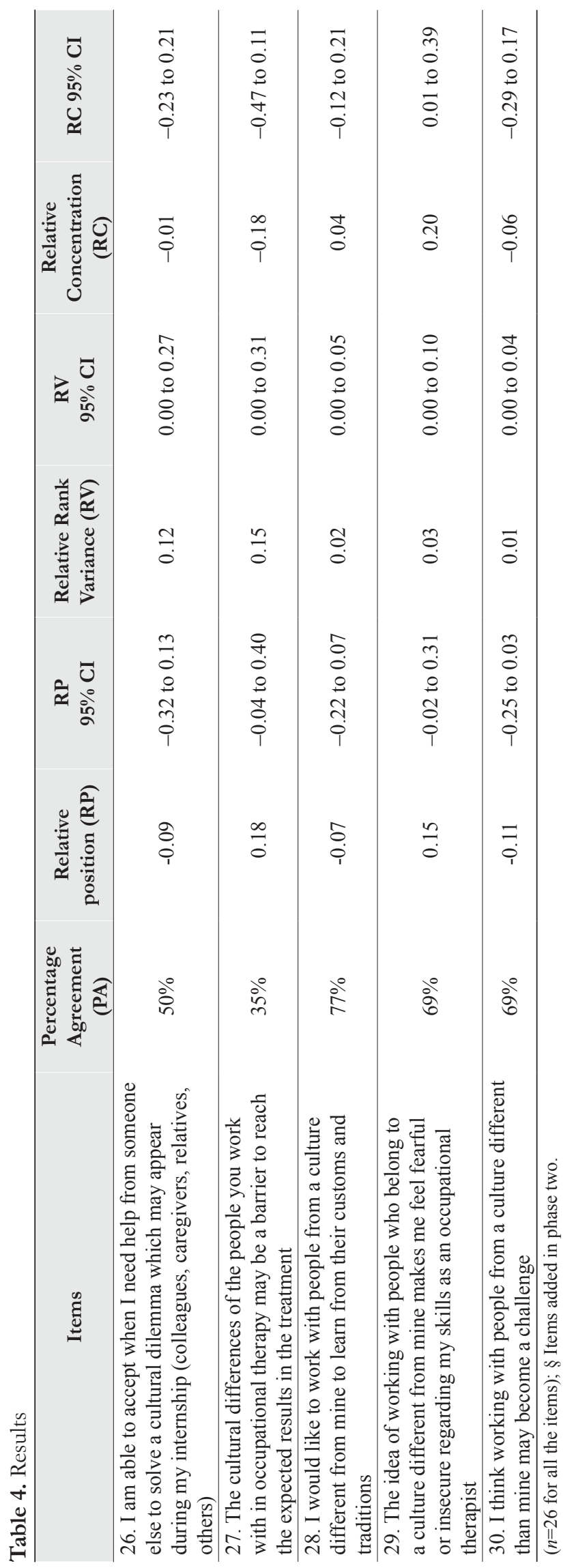


cultural awareness are developed through personal experiences (i.e. friends and/or travelling) and experiences acquired during professional education; therefore, variability within and between students groups may appear (WHITEFORD, 1995). It is also expected, that differences will emerge and some degree of error will be expressed in any measurement, based on the instability on the phenomena being measured, rather than the instrument itself (JOHNSTON; KEITH; HINDERER, 1992; SVENSSON, 1993). In the case of the test-retest reliability of the ECCETO, this instability might be related to students' fieldwork experiences. Contact with people during fieldwork will impact on their approach to cultural awareness, and students might have changed their responses between the test and retest (REW et al., 2014). It is also possible that some students changed placement in the 2 -week test-retest interval, and might have confronted new cultural realities (FITZGERALD et al., 2009).

In professional education, cultural awareness has been identified as a primary learning outcome of the fieldwork experience for healthcare students (LIPSON; DESANTIS, 2007). The ECCETO allows the current status of cultural awareness among occupational therapy students in Latin America to be measured, and provides the possibility to show individual and baselines cohorts. The ECCETO may be used for comparative studies, or as a way to identify potential cultural awareness weaknesses in a given program. The implementation of the scale should be accompanied by a guide for faculty members and students, including instructions for use of the scale, and general guidelines for interpretation of the results and connected activities. Given the diversity of elements addressed by the scale, qualitative strategies are recommended, such as diaries, reflective notes, or workshops to promote cultural awareness development (FITZGERALD et al., 2009). Using the scale without associated reflective strategies may result in insufficient development of cultural awareness (CASTRO; DAHLIN-IVANOFF; MÅRTENSSON, 2016a; FITZGERALD et al., 2009; KINÉBANIAN; STOMPH, 2009).

The clinical implications of cultural awareness include students' ability to implement more culturally aware practices in their fieldwork experience, creating the possibility of developing these in collaborative work with their supervisors. The ECCETO may also encourage the development of cultural awareness among faculty members and researchers, who may then implement modifications to curricula, open professional discussions and improved practices, based on reflections with students.
A complete comparison of the development and application of the CASQ and the ECCETO cannot be conducted at present (CASTRO; DAHLINIVANOFF; MÅRTENSSON, 2016a; CHEUNG; SHAH; MUNCER, 2002), particularly as there were differences in the respective development processes, language, notion of culture, and others aspects (CASTRO; DAHLIN-IVANOFF; MÅRTENSSON, 2016a; CHEUNG; SHAH; MUNCER, 2002). These differences provided the impetus to develop a new scale to assessing cultural awareness in Latin America, based on recently published theoretical data and empirical data collected from local practitioners (CASTRO; DAHLIN-IVANOFF; MÅRTENSSON, 2016a, b). The use of the two instruments in research also differs as since publication, the CASQ has been used in four related studies, whereas the ECCETO has not been used (CASTRO; DAHLIN-IVANOFF; MÅRTENSSON, 2016a; CHERRY et al., 2009; CHEUNG; SHAH; MUNCER, 2002; KALE; SWEE HONG, 2007; MURDEN et al., 2008; RASMUSSEN et al., 2005). Further investigation is required with larger groups of students to fully compare both instruments.

In the present study, the small number of participants and unequal representation of programs and countries should be considered as a potential weakness in interpreting the results. Representativeness is a common limitation in studies oriented to scale development (FITZGERALD et al., 2009). More participants may have provided a stronger indication of the scale's test-retest reliability, but voluntary participation and diversity in terms of countries were prioritised (SVENSSON, 1993). Other common limitations that should be considered when developing scales include: social desirability of responses, administrative issues, costs, and tiredness (KADAM; BHALERAO, 2010; KUMAS-TAN et al., 2007). The physical distance of the research team should also be considered as it may have a negative impact in the rate of responses to the invitation to participate (DOMHOLDT, 2005).

In terms of statistical analysis, the Svensson's method is considered superior in examining the disagreements separately. Unlike the Kappa coefficient (ALTMAN, 1991), Svensson's method does not only measure the degree of agreement between test and retest, but also provides a deeper understanding of underlying mechanisms that cause absence of agreement. As the response scale provided ordered categorical data, Cronbach's alpha coefficient, for which it is necessary to have items measured at an interval scale level, was not a viable alternative or complement for testing the reliability. 
In the test-retest of the ECCETO, an electronic version of the scale was used. Electronic assessments are commonly used in health care research (COPE, 2014). The possible barriers to using electronic assessments include limited access to technology and computer literacy, difficulties in remaining in contact with participants (lack of updated databases), uncertain response rates, and design requirements, among others (COPE, 2014; MCPEAKE; BATESON; O'NEILL, 2014). A low response rate may be related to lack of familiarity with the topic, tiredness given work/study or personal situations, and when students are exposed to tests and surveys on a regular basis (MCPEAKE; BATESON; O’NEILL, 2014).

The ECCETO should be applied with larger groups of occupational therapy students in Latin America to identify the most relevant cultural awareness features for their specific educational experiences. Further exploration should also focus on the development of similar scales for practitioners and faculties, and in other regions outside English-speaking countries, where the currently available scale has been designed and implemented (CHERRY et al., 2009; CHEUNG; SHAH; MUNCER, 2002; KALE; SWEE HONG, 2007; MURDEN et al., 2008; RASMUSSEN et al., 2005). Socio-historical conditions and practice contexts for occupational therapists also need to be addressed when research is being designed (GUAJARDO; KRONENBERG; RAMUGONDO, 2015). The eventual adaptation of the ECCETO to different countries must follow a strict process of cultural translation (WECHSLER et al., 2014), as the items in the present study were constructed and inspired by the experiences of Chilean occupational therapists, heads of participating programs and faculty members from a specific group of programs in Latin America, and therefore are not necessarily applicable to other countries (CASTRO; DAHLIN-IVANOFF; MÅRTENSSON, 2016a, b).

New and contextually developed and implemented scales to address culture and cultural awareness in occupational therapy may support the profession's transition to becoming less monoglossic (SAKELLARIOU; POLLARD, 2008). Monoglossia in occupational therapy means one voice presents and understands the main professional values and constructs, governed by the northern epistemologies, which has been described as Western knowledge (CASTRO; DAHLIN-IVANOFF; MÅRTENSSON, 2014; GUAJARDO; KRONENBERG; RAMUGONDO, 2015; HAMMELL, 2011). Moving towards a more heteroglossic profession may support the main aims of the profession (SAKELLARIOU; POLLARD, 2008), that is enabling people's participation in their daily lives, and considering their inner diversity and the multiplicity of voices and contexts that coexist in professional practice in the different regions (CASTRO; DAHLIN-IVANOFF; MÅRTENSSON, 2014; WORLD..., 2015).

The ECCETO's test-retest reliability and content validity have been studied in the present study and in our previous study (CASTRO; DAHLIN-IVANOFF; MÅRTENSSON, 2016a). The scale is showing promising psychometric properties to assess cultural awareness for occupational therapy students in Latin America. In future research, the ECCETO should be used in the construction of more culturally relevant education and more culturally aware practice in the Latin American region. Improved cultural awareness in students will be reflected in their awareness as practitioners, and will facilitate the implementation of practices that respond to the particular socio-historical conditions of Latin America (CASTRO; DAHLIN-IVANOFF; MÅRTENSSON, 2016a, b; GUAJARDO; KRONENBERG; RAMUGONDO, 2015).

\section{Conclusion}

The test-retest reliability evaluation of the ECCETO highlighted that the majority of items included in the scale are reliable in the form of stability over time (SVENSSON, 1993). These findings show the promising psychometric properties of the scale, and build on the content validity demonstrated in the previous study (CASTRO; DAHLIN-IVANOFF; MÅRTENSSON, 2016a).

\section{References}

AIKEN, L. R. Psychological testing and assessment. Boston: Allyn and Bacon, 2003.

ALTMAN, D. G. Practical statistics for medical research. London: Chapman and Hall, 1991.

AVDIC, A.; SVENSSON, E. Svensson's method. Örebro: Örebro Universitet, 2012. Available from: <http://www. oru.se/hh/Elisabeth-Svensson/Svenssons_metod/>. Access in: 5 jan. 2015.

BEAGAN, B. L. Approaches to culture and diversity: a critical synthesis of occupational therapy literature: des approches en matière de culture et de diversité: une synthèse critique de la littérature en ergothérapie. Canadian Journal of Occupational Therapy, Ottawa, v. 82, n. 5, p. 272-282, 2015.

CAMPINHA-BACOTE, J. The process of cultural competence in the delivery of healthcare services: a model of care. Journal of Transcultural Nursing, Thousand Oaks, v. 13, n. 3, p. 181-184, 2002. 
CASTRO, D.; DAHLIN-IVANOFF, S.; MÅRTENSSON, L. Occupational therapy and culture: a literature review. Scandinavian Journal of Occupational Therapy, London, v. 21, n. 6, p. 401-414, 2014.

CASTRO, D.; DAHLIN-IVANOFF, S.; MÅRTENSSON, L. Development of a Cultural Awareness Scale for Occupational Therapy Students in Latin America: a qualitative delphi study. Occupational Therapy International, Malden, v. 23, n. 2, p. 196-205, 2016a

CASTRO, D.; DAHLIN-IVANOFF, S.; MÅRTENSSON, L. Feeling like a stranger: negotiations with culture as experienced by Chilean occupational therapists. Scandinavian Journal of Occupational Therapy, London, v. 23, n. 6, p. 425-436, 2016 b.

CHERRY, K. et al. Cultural awareness and competency of graduate entry-level OT students. Education Special Interest Section Quarterly, Bethesda, v. 19, n. 3, p. 1-4, 2009.

CHEUNG, Y.; SHAH, S.; MUNCER, S. An exploratory investigation of undergraduate students' perceptions of cultural awareness. British Journal of Occupational Therapy, Thousand Oaks, v. 65, n. 12, p. 543-550, 2002.

COPE, D. G. Using electronic surveys in nursing research. Oncology Nursing Forum, Pittsburgh, v. 41, n. 6, p. 681-682, 2014.

DEVELLIS, R. F. Scale development: theory and applications. Thousand Oaks: SAGE Publications Inc, 2012.

DOMHOLDT, E. Rehabilitation research: principles and applications. St. Louis: Elsevier Saunders, 2005.

FITZGERALD, E. M.; CRONIN, S. N.; CAMPINHA-BACOTE, J. Psychometric testing of the Inventory for Assessing the Process of Cultural Competence Among Healthcare Professionals - Student Version (IAPCC-SV). Journal of Theory Construction \& Testing, Lisle, v. 13, n. 2, p. 64-68, 2009.

GALHEIGO, S. M. Identities, Latin American matters and knowledge production in Occupational Therapy: dialogues with Boaventura de Sousa Santos. Cadernos de Terapia Ocupacional da UFSCar, São Carlos, v. 22, n. 1, p. 215-221, 2014.

GUAJARDO, A.; KRONENBERG, F.; RAMUGONDO, E. L. Southern occupational therapies: emerging identities, epistemologies and practices. South African Journal of Occupational Therapy, Pretoria, v. 45, n. 1, p. 3-10, 2015.

HAMMELL, K. H. W. Resisting theoretical imperialism in the disciplines of occupational science and occupational therapy. British Journal of Occupational Therapy, Thousand Oaks, v. 74, n. 1, p. 27-33, 2011.

JOHNSTON, M. V.; KEITH, R. A.; HINDERER, S. R. Measurement standards for interdisciplinary medical rehabilitation. Archives of Physical Medicine and Rehabilitation, Philadelphia, v. 73, n. 12, p. 3-23, 1992.
KADAM, P.; BHALERAO, S. Sample size calculation. International journal of Ayurveda research, Mumbai, v. 1, n. 1, p. 55-57, 2010.

KALE, S.; SWEE HONG, C. An investigation of therapy student's perceptions of cultural awareness. International Journal of Therapy and Rehabilitation, London, v. 14, n. 5, p. 210-214, 2007.

KAZDIN, A. E. Artifact, bias, and complexity of assessment: the ABCs of reliability. Journal of Applied Behavior Analysis, Malden, v. 10, n. 1, p. 141-150, 1977.

KINÉBANIAN, A.; STOMPH, M. Diversity matters: guiding principles on diversity and culture. Forrestfield: World Federation of Occupational Therapists, 2009.

KLINE, T. Psychological testing: a practical approach to design and evaluation. Thousand Oaks: Sage Publications, 2005.

KUMAS-TAN, Z. et al. Measures of cultural competence: examining hidden assumptions. Academic Medicine, Albuquerque, v. 82, n. 6, p. 548-557, 2007.

LIPSON, J. G.; DESANTIS, L. A. Current approaches to integrating elements of cultural competence in nursing education. Journal of Transcultural Nursing, Thousand Oaks, v. 18, n. 1, p. 10-20, 2007.

MCPEAKE, J.; BATESON, M.; O’NEILL, A. Electronic surveys: how to maximise success. Nurse Researcher, Harrow, v. 21, n. 3, p. 24-26, 2014.

MUNIIZ, J. et al. Testing practices in European countries. European Journal of Psychological Assessment, Boston, v. 17, n. 3, p. 201-211, 2001.

MURDEN, R. et al. Occupational therapy students' perceptions of their cultural awareness and competency. Occupational Therapy International, Malden, v. 15, n. 3, p. 191-203, 2008.

NUNNALLY, J. C.; BERNSTEIN, I. H. Psychometric theory. New York: McGraw-Hill, 1994.

ODAWARA, E. Cultural competency in occupational therapy: beyond a cross-cultural view of practice. American Journal of Occupational Therapy, Bethesda, v. 59, n. 3, p. 325-334, 2005.

RASMUSSEN, T. M.; LLOYD, C.; WIELANDT, T. Cultural awareness among Queensland undergraduate occupational therapy students. Australian Occupational Therapy Journal, Melbourne, v. 52, n. 4, p. 302-310, 2005.

REW, L. et al. Measuring cultural awareness in nursing students. Journal of Nursing Education, Thorofare, v. 42, n. 6, p. 249-257, 2003.

REW, L. et al. Cultural diversity among nursing students: reanalysis of the cultural awareness scale. Journal of Nursing Education, Thorofare, v. 53, n. 2, p. 71-76, 2014.

SAKELlarioU, D.; POLLARD, N. Political challenges of holism: heteroglossia and the (im)possibility 
of holism. In: POLLARD, N.; SAKELLARIOU, D.; KRONENBERG, F. A political practice of occupational therapy. Edinburgh: Churchill Livingstone Elsevier, 2008. p. 91-106.

SVENSSON, E. Analysis of systematic and random differences between paired ordinal categorical data. Stockholm: Almqvist \& Wiksell International, 1993.

SVENSSON, E. Ordinal invariant measures for individual and group changes in ordered categorical data. Statistics in Medicine, Hoboken, v. 17, n. 24, p. 29232936, 1998.

SVENSSON, E. Guidelines to statistical evaluation of data from rating scales and questionnaires. Journal of Rehabilitation Medicine, Uppsala, v. 33, n. 1, p. 47-48, 2001.

WECHSLER, S. M. et al. Test development and use in five Iberian Latin American countries. International Journal of Psychology, Hoboken, v. 49, n. 4, p. 233-239, 2014.
WHITEFORD, G. E. Other worlds and other lives: a study of occupational therapy student perceptions of cultural difference. Occupational Therapy International, Malden, v. 2, n. 4, p. 291-313, 1995.

WORLD FEDERATION OF OCCUPATIONAL THERAPISTS - WFOT. Revised minimum standards for the Education of Occupational Therapists. Forrestfield: WFOT, 2002.

WORLD FEDERATION OF OCCUPATIONAL THERAPISTS - WFOT. Entry level approved educational programmes WFOT. Forrestfield: WFOT, 2014. Available from: <http://www.wfot.org/Education/EntrylevelEducationalProgrammesWFOTApproved.aspx>. Access: 31 jul. 2014.

WORLD FEDERATION OF OCCUPATIONAL THERAPISTS - WFOT. Definition of Occupational Therapy. Forrestfield: WFOT, 2015. Available from: <http://www.wfot.org/AboutUs/AboutOccupationalTherapy/DefinitionofOccupationalTherapy.aspx $>$. Access: 02 dec. 2015.

\section{Author's Contributions}

Daniela Castro: study design, data collection and analysis, manuscript writing. Synneve Dahlin-Ivanoff: study design, assistance in data analysis, and revision of the text. Lena Mårtensson: study design, assistance in data analysis, text writing and revision of the text. All authors approved the final version of the manuscript. 